\title{
Psycho-emotional disorders in women after spontaneous abortion
}

\author{
Gustavo Romero-Gutiérrez ${ }^{1}$, Nancy Pérez-Durán ${ }^{2}$, Ana Camarillo-Trujillo ${ }^{2}$, \\ Armando Ruiz-Treviño ${ }^{1}$ \\ ${ }^{1}$ Dept. Obstetrics and Gynecology. UMAE. Hospital de Gineco-Pediatría No 48, IMSS, León, Guanajuato. México \\ ${ }^{2}$ Dept. Clinic Psychology. UMAE Hospital de Gineco-Pediatría No 48, IMSS, León, Guanajuato, México
}

\section{Email address:}

gustavoromerog@hotmail.com (G. Romero-Gutiérrez),psic_nancyperez@hotmail.com (N. Pérez-Durán), rubia_2023@yahoo.com.mx (A.Camarillo-Trujillo), armando.ruiz.t@gmail.com (A. Ruiz-Treviño)

\section{To cite this article:}

Gustavo Romero-Gutiérrez, Nancy Pérez-Durán, Ana Camarillo-Trujillo, Armando Ruiz-Treviño. Psycho-Emotional Disorders in Women after Spontaneous Abortion, Clinical Medicine Research. Vol. 2, No. 2, 2013, pp. 6-10. doi: 10.11648/j.cmr.20130202.11

\begin{abstract}
Objective: To determine the frequency of women with spontaneous abortions that present psycho-emotional disorders. Design: Cross-sectional study using a face-to-face questionnaire. Setting: Postpartum area at a tertiary care referral hospital in Leon, Mexico. Participants: 210 postpartum women, divided into 105 women with spontaneous abortion, and 105 with eutocic deliveries (controls). Data collection: Women answered face-to-face the questionnaire Minnesota Multiphase Personality Inventory-2 (MMPI-2), applied one day after the abortion. Findings: the frequency of psycho-emotional disorders in women who presented abortion was $(12.7 \%)$, which was higher compared with the controls $(9.04 \%), \mathrm{P}=0.002$, being significant the hysteria $(6.6 \%), \mathrm{P}=0.021$. Key conclusions: There is a higher frequency of psycho-emotional disorders in women who present an abortion, represented for hysteria. Implications for practice: It is recommended to supply psychological support to women who suffer a spontaneous abortion.
\end{abstract}

Keywords: Spontaneous Abortion, Psycho-Emotional Disorders, Minnesota Multiphase Personality Inventory-2 (MMPI-2)

\section{Introduction}

Spontaneous abortion is a serious pregnancy complication affecting approximately $30 \%$ of biochemical pregnancies and about $11-20 \%$ of clinically recognized pregnancies [1]. It is defined as the spontaneous loss of a fetus before twenty weeks of pregnancy. A spontaneous abortion may also be called a miscarriage. This refers to naturally occurring events, not medical abortions or surgical abortions [2].

Abortion represents a complex biological and psychological event, which is regarded as a difficult and distressing life event for a woman. For many women, abortion may represent the loss of a future child, of motherhood, and of part of self; and it may engender doubts regarding the ability to procreate. The symptoms of distress response after spontaneous abortion include psychological, physical, cognitive and behavioral effects [3].

Spontaneous abortion is the most common adverse pregnancy outcome, and stress has been suggested to be an important subsequent factor. Previous studies have documented that women who had experienced miscarriage or stillbirth had significantly higher levels of anxiety and depression in a subsequent pregnancy [4]. Recently it has been reported that pregnant women with previous spontaneous abortion, have higher anxiety and depression than pregnant women without this complication [5]. Another study conducted in Berlin, Germany indicated that, compared to women without spontaneous abortions, women with prior spontaneous abortion had higher levels of pregnancy-related fear and state anxiety during the first trimester [6].

Abortion can provoke feelings of lost and grief reaction. Some general population studies point out significant association between mood alterations like depression and some anxiety disorders [7].

There is also evidence that a miscarriage may lead to acute stress disorder and posttraumatic stress disorder [8]. After spontaneous abortion, as many as 10 percent of women may have acute stress disorder and up to 1 percent may have post-traumatic stress disorder [3]. Moreover, a research carried out in New Zealand, reported that young women having an abortion had elevated rates of subsequent 
mental health problems, including depression, anxiety and suicidal behaviors. These findings suggest that abortion in young women may be associated with increased risks of mental health problems [9].

Some risk factors for psychological disorders present in women who undergo an abortion include ambivalence about the decision, level of social support and whether or not the pregnancy was originally intended [10]. There are lacking studies worldwide, regarding other psycho-emotional disorders that may occur in women who experience spontaneous abortion. Our aim was to determine the frequency of psycho-emotional disorders in these women at immediate delivery, in a developing country setting.

\section{Methods}

\section{Design and Settings}

A cross-sectional study was conducted at the Hospital of Obstetrics and Gynecology at the Mexican Institute of Social Security located in Leon, Mexico, from February to December, 2011. During this period, the recruitment was carried out from the patients who were hospitalized; and with a computer program of random numbers, they were progressively included until the sample was completed. Women were invited to participate at one day after delivery; this date was assigned conventionally because at our hospital postpartum women are discharged during this time.

The study protocol was approved by the ethics and research committee of the local institutional review board; and women who agreed to participate in the study completed a written informed consent form. The recruited women answered face-to-face questions from the Minnesota Multiphasic Personality Inventory-2 (MMPI-2) administered one day after delivery in a Spanish language applied by researchers N. Pérez-Durán and A. Camarillo-Trujillo who were both interviewers and interpreters of the test.

\section{Participants}

Two-hundred and ten women were divided into two groups: One-hundred and five women who had a spontaneous abortion between the range of 18 and 41 years (Mean age $26.4 \pm 0.5)$ and one-hundred and five women who had a eutocic delivery (Mean age $24.9 \pm 0.4$ ). The patients were recruited according to the following:

Inclusion criteria: Women between 18 to 41 years old, whose abortion was treated in our hospital.

Exclusion criteria: Patients whose product has been stillbirth, induced abortions, patients who did not complete high school and patients under 18 years old.

Elimination criteria: Patients whose responses showed inconsistencies and met the criteria for determining invalidity according to the applied MPPI-2.

\section{Sampling Procedures}

Random-number tables were used to select the same number of women with spontaneous abortion compared to women who had a eutocic delivery among all postpartum women admitted to the hospital.

Instruments
The psychological assessment consisted in clinical interviews and administration of MMPI-2. The test is a recent version of the original MMPI that was designed to help identify personal, social, and behavioral problems in psychiatric patients. This MMPI-2 edition can be used in healthy individuals, and this questionnaire has been validated in a population of pregnant women [11]. The MMPI-2 has 42 scales and the clinical and validity scales are graded with the 370 first items. These validity scales are used to determine accuracy in the patient's response. According to responses of women 17 psycho-emotional disorders can be categorized by reaching a specific number of positive answers [12].

Because of possible participation of regional characteristics, we evaluated some socio-demographic variables of our population, as well as clinical factors; the factors registered were: maternal age, which was defined as completed years at the time of delivery; marital status, which was registered as 0 if the mother was currently married and as 1 if the mother had never married or was divorced, separated, or widowed (single women); education level, which was registered as the number of completed years of school; maternal occupation, which was categorized as 0 if the woman had no formal occupation and as 1 if she had employment outside the home (working women); parity, which was defined as the number of previous births; previous pregnancies, including abortions; antenatal care, which was categorized as 0 when the woman received no antenatal care at the hospital and 1 , when she attended at least one appointment in the antenatal care department; the number of antenatal visits for each woman, coded as the current number of prenatal appointments during the pregnancy; acceptance of a contraceptive method after the present pregnancy; and the following variables were registered conventionally as yes $=1$ or not $=0$, according to responses of women about: enough and accurate medical advice during antenatal care; family support during pregnancy; interfamilial violence and obstetric complications.

\section{Data Analysis}

Data were analyzed using descriptive statistical analysis which included arithmetic mean, standard error (SE) and percentages. The groups were compared using the Chi-square analysis or Fisher Exact' test for categorical variables; and Student t' test or Mann-Whitney U test for continuous variables as appropriate depending on their normal distribution, the alpha value was set at 0.05 . Statistical analysis was performed with the Number Cruncher Statistical System computer program [13].

\section{Results}

In the entire sample $(\mathrm{N}=210)$, the maternal mean age (with standard error SE in parentheses) was $25.7( \pm 0.2)$ years, the women ranged in age from 18 to 41 . The age of the women with spontaneous abortion was $26.4( \pm 0.5)$, while the controls was $24.9( \pm 0.4), \mathrm{P}=0.026$. One-hundred fifty-two women were married $(70.2 \%)$. The percentage of women who had employment outside their home was higher 
in patients with abortion, seventy-four women with spontaneous abortion $(70.4 \%)$ worked outside home and fifty-five women of the control group $(52.3 \%)$ worked outside home, $\mathrm{P}=0.011$ (table 1 ).

Table 1. Univariate analysis of socio-demographic characteristics between the groups. (Mean $\pm S E ; n(\%)$.

\begin{tabular}{llll}
\hline Variable & $\begin{array}{l}\text { Women with } \\
\text { abortion } \\
(\mathbf{n = 1 0 5})\end{array}$ & $\begin{array}{c}\text { Controls } \\
(\mathbf{n = 1 0 5})\end{array}$ & $\mathbf{P}$ \\
\hline $\begin{array}{l}\text { Maternal } \\
\text { (years) }\end{array}$ & $26.4 \pm 0.5$ & $24.9 \pm 0.4$ & 0.026 \\
$\begin{array}{l}\text { Education } \\
\text { level (years) } \\
\text { Marital }\end{array}$ & $10.5 \pm 0.1$ & $10.5 \pm 0.2$ & 0.843 \\
$\begin{array}{l}\text { Status } \\
\text { (single }\end{array}$ & $30(28.5)$ & $28(26.6)$ & \\
$\begin{array}{l}\text { women) } \\
\text { Family } \\
\text { support }\end{array}$ & $6(5.7)$ & $3(2.8)$ & 0.877 \\
Working & $74(70.4)$ & $55(52.3)$ & 0.496 \\
women & & & 0.011 \\
\hline
\end{tabular}

In the analysis of the clinical characteristics we found that the significant factors were the following: the number of previous pregnancies, that was higher in the control group, $\mathrm{P}$ $=0.001$; the number of medical consultations, that was higher in the control group, $\mathrm{P}=0.001$; the number of obstetric complications, that was higher in women with abortion, $\mathrm{P}=0.001$; the number of psycho-emotional disorders that was higher in women with abortion, $\mathrm{P}=0.002$, and the medical information that was higher in women with not abortion, $\mathrm{P}=0.001$, (table 2 ).

Table 2. Univariate analysis of clinical factors between the groups.

\begin{tabular}{|c|c|c|c|}
\hline Variable & $\begin{array}{l}\begin{array}{l}\text { Women } \\
\text { with abortion } \\
(\mathrm{n}=105)\end{array} \\
\end{array}$ & $\begin{array}{l}\text { Controls } \\
(n=105)\end{array}$ & $\mathbf{P}$ \\
\hline Previous pregnancies & 0.8 & 1.8 & 0.001 \\
\hline Previous abortions & $23(21.9)$ & $15(14.2)$ & 0.210 \\
\hline $\begin{array}{l}\text { Number of antenata } \\
\text { visits }\end{array}$ & $\mathrm{al}_{1.7}$ & 10.7 & 0.001 \\
\hline Obstetric complications & $53(50.4)$ & $28(26.6)$ & 0.001 \\
\hline $\begin{array}{l}\text { Psycho-emotional dis- } \\
\text { order }\end{array}$ & s- 14 (12.7) & $10(9.0)$ & 0.002 \\
\hline Tobacco abuse & $6(5.7)$ & $4(3.8)$ & 0.746 \\
\hline Interfamilial violence & $9(8.5)$ & $8(7.6)$ & 1.000 \\
\hline Medical advice & $42(40)$ & $14(13.3)$ & 0.001 \\
\hline Contraceptive acceptance & e21 (20) & $17(16.1)$ & 0.591 \\
\hline
\end{tabular}

The frequency of women with psycho-emotional disorders who presented abortion was $12.7 \%$, compared with controls who had $9.04 \%, P=0.002$. Depression was tended to be significant, $\mathrm{P}=0.064$, but hysteria was the only significant variable, which was found in a $6.6 \%$ of women with spontaneous abortion, compared with $0 \%$ in women without abortion, $\mathrm{P}=0.021$, (table 3 ).
Table 3. Comparison of the psycho-emotional disorders between women with spontaneous abortion and controls; $n(\%)$.

\begin{tabular}{|c|c|c|c|}
\hline \multicolumn{4}{|l|}{$\begin{array}{l}\text { Psycho-emotional } \\
\text { disorder }\end{array}$} \\
\hline & $\begin{array}{l}\text { Women with } \\
\text { abortion } \\
\mathrm{n}=105\end{array}$ & $\begin{array}{c}\text { Controls } \\
(\mathrm{n}=105)\end{array}$ & $\mathrm{P}$ \\
\hline Hypochondriasis & $7(6.6)$ & $4(3.8)$ & 0.536 \\
\hline Depression & $23(21.9)$ & $1(0.9)$ & 0.064 \\
\hline Hysteria & $7(6.6)$ & $0(0)$ & 0.021 \\
\hline $\begin{array}{l}\text { Psychopathic } \\
\text { deviate }\end{array}$ & $6(5.7)$ & $2(1.9)$ & 0.279 \\
\hline $\begin{array}{l}\text { Femininity role } \\
\text { rejection }\end{array}$ & $\mathrm{e}_{2(1.9)}$ & $2(1.9)$ & 1.000 \\
\hline Paranoia & $15(14.2)$ & $7(6.6)$ & 0.115 \\
\hline Psychasthenia & $11(10.4)$ & $10(9.5)$ & 1.000 \\
\hline Schizophrenia & $10(9.5)$ & $11(10.4)$ & 1.000 \\
\hline Hypomania & $22(20.9)$ & $24(22.8)$ & 0.867 \\
\hline $\begin{array}{l}\text { Social introver- } \\
\text { sion }\end{array}$ & $15(14.2)$ & $11(10.4)$ & 0.530 \\
\hline Anxiety & $24(22.8)$ & $14(13.3)$ & 0.107 \\
\hline Health concern & $10(9.5)$ & $5(4.7)$ & 0.284 \\
\hline Anger & $20(19)$ & $18(17.1)$ & 0.858 \\
\hline Low self-esteem & $15(14.2)$ & $13(12.3)$ & 0.839 \\
\hline
\end{tabular}

\section{Discussion}

Pregnancy is not only a medical but also a psychological and social event. There are many situations combined with pregnancy that in medical terms, constitute a risk, danger or failure and result in a wide range of emotional reactions in a woman that require special care and attention for her psychological functioning [14].

Recently, it has been reported that compared to women who had never had an abortion, women who had reported an abortion were at an increased risk of several anxiety and mood disorders [15]. In our study the results were similar, and the patients with spontaneous abortion presented higher percentages of anxiety and depression, compared with women who not.

However, the hysteria was the only significant variable in our study. This disorder can be explained because women showed an unusual personality pattern, which includes social performance characterized by denial and extravagance. Also, they had reflected specific physical complaints or disorders such as denial of psychological or emotional problems. The five content areas identified by Harris-Lingoes are: social anxiety denial, affection need, malaise-fatigue, somatic complaints and aggression inhibition [12].

Women who presented abortion were more anxious and depressed, as shown by later life events, full of problematic feelings and the need for psychological support [16]. The disorders we observed in our study may have been influenced by the fact that the questionnaire was applied in the first twenty-four hours of the surgical procedure, and most 
probably women's first reaction to spontaneous abortion is sadness and guilt, in this period of time they show negative feelings including depression and anxiety traits.

The family environment involvement, specially the control by the husbands over the marital relationship and neurotic personality traits of the women increased the emotional distress, whereas the social support the women perceive decreased it. These findings suggest that marital and social support is important in determining the level of psychiatric morbidity after repeated abortions [17].

Recent research has revealed that health professionals often tend to neglect this factor. This omission can lead to delayed diagnosis and appropriate care. Health professionals should be aware of the psychological complications associated with spontaneous abortion, and also be sensitive to current unsatisfied need for psychological care [18].

Some authors have reported the importance of psychological counseling which is beneficial in reducing women's distress after a spontaneous abortion [19]. According to the above, it is suggested the intervention of an interdisciplinary team for a proper management of adverse obstetric events. The interdisciplinary team would consist by a psychologist, obstetrician/gynecologist, midwife and social workers trained to handle the crisis situation and duel, so that women can cope with this difficult situation and return as soon as possible to their normal activities.

It is important that women be provided with the adequate detailed information on the reason why was performed a curettage and the consequences of not performing this procedure, and let them know about the alternatives and the care required for a future pregnancy.

Early detection of possible psycho-emotional disorder can raise a suitable psychological intervention; this would help to prevent a severe disruption that would affect the integrity of the psychological health of the patient. At the same time, it is suggested to design an integrated treatment with the possibility of reducing the psychosomatic risks that may affect the product during the gestation period, and also, to reduce the incidence of spontaneous abortions in its different dimensions.

There are limitations to our study. The design of the research is weak because it is important to control for psychopathology before pregnancy and other confounding effects. Since the application of the questionnaire was done at immediate post-abortion and the answers might have been influenced by state of the women with respect to complications that developed during pregnancy and delivery.

Although the MMPI-2 is a clinical testing instrument that has been internationally validated and is considered the most comprehensive index for detecting personality and emotional disorders, it is complex and time-consuming, and should be used in conjunction with other assessment tools. Diagnosis should never be made solely on the results of the MMPI- 2 test.

However, our findings have shown a very high frequency of psychological disorders in post abortion women, this information has been poorly described in developing coun- try women; this knowledge could help the health team worldwide, in order to adequate global strategies. In this manner, the psychological condition of these women could be enhanced.

We suggest screening not only for depression but also for more comprehensive psycho-emotional disorders that could be identified earlier such as screening to be done during pregnancy or at immediate post-abortion. It should be noted that according to the results obtained in our investigation, the emotional elements are a critical part that is linked to a physical factor that can promote good health or decrease it, resulting in lower or higher risks. It is also very important to consider that there are environmental and social factors that can be altered by presenting spontaneous abortion or other adverse obstetric event. Psychological support could then be provided to the women, who aborted, with a referral to specialized treatment if necessary.

\section{Conclusion}

There is a high incidence of psycho-emotional disorders in women that suffer an abortion. The significant disorder is the hysteria. We recommend a comprehensive and immediate counseling to women with spontaneous abortion.

\section{References}

[1] Bottomley C, Bourne, T. Diagnosing miscarriage. Best practice \& research. Clinical obstetrics \& gynaecology 2009; 23: 463-77.

[2] Katz VL, Lentz GM, Lobo RA, Gershenson D M. [Eds.] Pa: Mosby Elsevier Spontaneous and recurrent abortion: etiology, diagnosis, treatment. In: Comprehensive Gynecology. Philadelphia: 2007; 16.

[3] Bowles SV, James LC, Solursh DS, Yancey MK, Epperly T D, Folen RA, Masone M. Acute and post-traumatic stress disorder after spontaneous abortion. American family physician 2000; 61: 1689-1696.

[4] Blackmore ER, Côté-Arsenault D, Tang W, Glover V, Evans J, Golding J, O'Connor, TG. Previous prenatal loss as a predictor of perinatal depression and anxiety. The British journal of psychiatry 2011; 198: 373-378.

[5] Marcinko VM. Marcinko D, Dordević V, Oresković S. Anxiety and depression in pregnant women with previous history of spontaneous abortion. Collegium antropologicum $2011 ; 35 ; 225-228$.

[6] Geller PA, Kerns D, Klier CM. Anxiety following miscarriage and the subsequent pregnancy: a review of the literature and future directions. Journal of psychosomatic research 2004; 56: 35-45.

[7] Gurpegui M, Jurado D. Psychiatric complications of abortion. Cuadernos de bioética: revista oficial de la Asociación Española de Bioética y Ética Médica 2009; 20: 381-392.

[8] Lee C, Slade P. Miscarriage as a traumatic event: a review of the literature and new implications for intervention. Journal of psychosomatic research 1996; 40: 235-244. 
[9] Fergusson DM, Horwood LJ, Ridder EM. Abortion in young women and subsequent mental health. Journal of child psychology and psychiatry, and allied disciplines 2006; 47 : $16-24$.

[10] Cameron, S. Induced abortion and psychological sequelae. Best practice \& research. Clinical obstetrics \& gynaecology 2010; 24: 657-665.

[11] D'Orazio LM, Meverowitz BE, Korst LM, Romero R, Goodwin TM. Evidence against a link between hyperemesis gravidarum and personality characteristics from an ethnically diverse sample of pregnant women: a pilot study. J womens health (Larchmt) 2011; 20: 137-144.

[12] Hathawey S.R, McKinley JC. Inventario Multifásico de la Personalidad de Minesota-2 (MPPI-2) [Minnesota Multiphasic Personality Inventory-2]. 1995, México, DF: El Manual Moderno.

[13] Hintze, J. (2008). Number Cruncher Statistical System. Kaysville, Utah: Statistical software, 2005. Retrieved from http://www.ncss.com.

[14] Luczak-Wawrzyniak J, Czarnecka-Iwanzuk M, Bukowska A, Konofalska N. Early and late psychological effects of pregnancy loss. Ginekologia polska 2011; 81: 374- 377.
[15] Steinberg JR, Finer LB. Examining the association of abortion history and current mental health: A reanalysis of the National Comorbidity Survey using a common-risk-factors model. Social science \& medicine 2011; 72: 72-82.

[16] Benute GR, Nomura RM, Pereira PP, Lucia MC, Zugaib M. Spontaneous and induced abortion: anxiety, depression and guilty. Revista da associação médica brasileira 2009; 55: 322-327.

[17] Hori S, Nakano Y, Yamada A, Azuma H, Noda Y, Sugiura M, Furukawa TA. Personality, social support, coping and emotional distress after repeated spontaneous abortions. Journal of psychosomatic obstetrics and gynaecology 2002; 23: 133-140.

[18] Kong GW, Lok IH, Lam PM, Yip AS, Chung TK. Conflicting perceptions between health care professionals and patients on the psychological morbidity following miscarriage. The Australian \& New Zealand journal of obstetrics \& gynaecology 2010; 50: 562-567.

[19] Nikcević AV, Kuczmierczyk AR, Nicolaides KH. The influence of medical and psychological interventions on women's distress after miscarriage. Journal of psychosomatic research 2007; 63: 83-90. 